\title{
Iluminação cênica: espaço, luz e corpos em foco
}

Stage lighting: space, light and bodies in focus

Laura Maria de Figueiredo ${ }^{1}$ 


\section{Resumo}

Este artigo descreve algumas das articulações entre espaço, luz e corpos nos palcos e que resultam em signos visuais, atmosferas dramáticas ou outras configurações significantes na cena. Por meio desta leitura procuro apontar alguns dos elementos materiais que constituem bases técnicas para analisar o fenômeno poético da luz cênica.

Palavras-chave: Iluminação cênica, espaço; corpo

\section{Abstract}

This article describes some of the articulations between space, light and bodies on the stages which results in visual signs, dramatic atmospheres or others significances configurations in the scene. Through this reading I try to point out some of the material elements concerns technical quotes for analyzing the poetic phenomenon of stage lighting.

Keywords: Stage lighting; space; body

ISSN: 1414.5731

E-ISSN: 2358.695

${ }^{1}$ Professora Assistente, Mestre. Curso de Licenciatura em Artes. Universidade Federal do Rio Grande do Norte (UFRGN). Diretora Teatral e lluminadora Cênica. llaufigueiredo@gmail.com 
Mas se, como todo bom frequentador de teatro, você vai ao teatro para ver o que queremos lhe mostrar, você verá isso se nós formos realmente bons trabalhadores do teatro.

(Edward Gordon Craig, 2017, p. 224)

O trabalho da iluminação atuando na cena como linguagem já é um dado preciso e relevante a ser considerado em qualquer produção teatral, seja ela executada sob a luz natural ou artificial. Cibele Forjaz destacou o papel da iluminação como portadora de uma linguagem cênica desde os primórdios do teatro ocidental, que "cria significados e dá estrutura às mudanças de espaço e de tempo" (Forjaz, 2013 p.152).

Deste universo de significações proposto pela linguagem da iluminação cênica se destacam os aspectos dos discursos pelas imagens, e o trabalho de Eduardo Tudella, traz uma vasta análise da iluminação cênica sob esse prisma, considerando que na práxis cênica as imagens produzem uma "qualidade muito particular devido à sua interação imediata com o espectador" e "tornou indispensável considerar a cena um discurso poético-visual" (Tudella, 2013 p. 46). Este autor (2013, p. 45) defende que o teatro "precisa de críticos que tenham incluído em sua formação a educação visual, o que os autorizaria a avaliar de maneira consistente a contribuição da luz em um evento cênico".

Seguindo esse chamado à educação visual, este trabalho elenca certos elementos formais constitutivos das bases materiais que a iluminação teatral manuseia para atuar sobre as cenas. Ponho em relevo aspectos destas materialidades que interagem para a criação de imagem e linguagem na cena, colocando em foco questões de espaço, fontes de luz e corpo humano em movimentos interativos.

Procuro trazer exemplos ilustrativos por meio de textos elaborados por cenógrafos e teóricos fundadores de poéticas da iluminação cênica como Edward Gordon Craig (1872-1966) e Adolphe Appia (1862-1928), ou por um ator, diretor e dramaturgo como Dario Fo (1926-2016), que traz um aporte singular em suas pesquisas sobre atuação no Teatro, apesar de não ter sido um iluminador cênico. As reflexões finais tematizam as possibilidades de análises por meio de um olhar educado para enxergar muito além das impressões definidas por platitudes como beleza e magia. Essa educação treinará o olhar do espectador para observar as relações entre espaço, luz e corpos em movimento como base para composições visuais, que poderão gerar camadas de percepção e interpretação do trabalho da iluminação cênica nos espetáculos.

\section{Arquitetura teatral, fonte de luz, corpo humano e espaço}

Quando o Teatro passou a ser realizado dentro de edifícios especialmente projetados para os fins de configurar o espaço de encontro entre artistas cênicos e suas plateias, a arquitetura teatral tornou-se um ponto de confluência para o desenvolvimento das tecnologias que desde então oferecem suporte, tanto para enunciação de conteúdos cênicos no palco; como para recepção sensorial a estes estímulos dirigidos à plateia. Cada arquitetura estabelece a forma de organizar a interação palco/ plateia, e as tipologias tradicionais que se mantêm como formas consolidadas e presentes até hoje são: arena grega, palco elisabetano, palco italiano. Revisitando essas 
tipologias em suas reflexões, Edward Gordon Craig fez uma instigante provocação quando afirma: "naqueles dias, eles construíam seus teatros para os seus dramas, não seus dramas para seus teatros" (Craig, 2017, p.52).

$\mathrm{Na}$ atualidade, as artes cênicas operam com um sentido de espaço que:

Pode ser entendido como a arquitetura teatral, o espaço cênico e cenográfico onde se deslocam os intérpretes, e o espaço subjetivo dramatúrgico, criado pelo artista e sua interpretação repleta de significados para o público, sendo este último, juntamente com a cenografia, um ponto de vista e uma focalização. (Soares, 2016, p. 44). ${ }^{2}$

O sentido de arquitetura teatral e espaço cênico ampliaram-se para uma diversidade de proposições de relação palco/plateia no teatro contemporâneo, mas as formas tradicionais ainda são marcos para entendermos as configurações dos campos de visão e interação entre os corpos e olhares que participam de espetáculos cênicos seja na cena, seja na plateia. Abordarei algumas das características das técnicas desenvolvidas por iluminadores cênicos para cumprir esse papel de configurar pontos de vista, focos de atenção, movimentos e olhares diferenciados sobre o espaço e as imagens daí derivadas.

Em Manual Mínimo do Ator Dario Fo (1998) destaca as relações dos atores/atrizes com as tecnologias cênicas: figurino, maquiagem e enfatiza os elementos de espaço e luz como recursos técnicos e estéticos que têm seu papel na comunicação destes artistas com seu público. Para tanto ele descreve a relação palco/plateia do edifício teatral de Epidauro, exemplar da arquitetura que abrigou o espetáculo da tragédia grega

Os espectadores viam os atores de cima para baixo, ou seja, obliquamente. As costas dos atores eram alargadas ao máximo para o aproveitamento integral desse efeito. [...] havia uma projeção de sombra obtida por meio de grandes espelhos, causando uma ilusão de maior grandeza dos personagens. A palavra refletor (anaclátoras, em grego) parece ter sua origem nesse sistema. [...]. De fato, sobre grandes discos de madeira - escudos gigantes - colavam-se lâminas de mica reflexiva. Os espelhos eram móveis, permitindo o acompanhamento do sol, captura de seus raios e a projeção sobre o espaço cênico. (Fo, 1998, p.258)

O teatro de Epidauro tinha seu theatron (local da plateia) voltado para o sul, e a sua skéne (local do palco) voltada para o norte. Como se sabe o sol era a fonte da luz cênica para o espetáculo grego no século $V$ a.C, sobre esse edifício sem cobertura.

As apresentações aconteciam no inverno europeu de dezembro a março e como demonstrou Cardoso (2010): "No teatro de Epidauro sua orientação é para norte, com o sol nascendo a leste percorrendo seu trajeto pelo sul até se por no oeste, mantendo-se sempre frontal à plateia". Com esta perspectiva entendemos melhor os espelhos refletores descritos por Dario Fo na medida em que vislumbramos que o sol percorria o céu nascendo por trás da skéne e mantinha-se na frente do theatron durante grande parte das apresentações, e estudos demonstram que:

\footnotetext{
2"Puede ser entendido como la arquitectura teatral, el espacio escénico y escenográfico donde se desplazan los interpretes, y el espacio subjetivo dramaturgico, creado por el artista y su interpretación y lleno de significados para el publico, siendo este último, juntamente con la escenografía, un punto de vista y una focalización". (Tradução nossa).
} 
$\mathrm{Na}$ Grécia o Sol nunca assume a posição perpendicular em relação à Terra, e durante o inverno sua elevação situa-se entre $30^{\circ}$ e o máximo de $50^{\circ}$, entre $12 \mathrm{~h} 00 \mathrm{~min}$ e 13h00minh, não criando uma sensação desagradável ao permanecermos sob sua luz durante todo o dia, que, aliás, duras dez horas em média. (Cardoso, 2010, p.5)

O autor italiano escreve sobre o efeito de luz obtido durante o espetáculo para destacar deuses e heróis:

Por meio dos espelhos refletores conseguia-se projetar uma luz exatamente sobre os atores, em uma diagonal preestabelecida. Podia-se também refletir o feixe de luz em duas etapas: um espelho colocado na encosta da colina capturava os raios solares e projetava-os sobre outro espelho localizado em um plano inferior, que, por sua vez, lançava a luz praticamente rente ao palco. O resultado obtido era notável, intensificando-se o efeito da obliquidade. De fato, ao se estender a sombra projetada por um objeto, temos a impressão de que ele tornou-se mais alto, Portanto, iluminando-se os atores desse modo, devido ao alongamento da sombra, garantia-se o efeito do agigantamento. (Fo, 1998, p.259)

Tal exemplo nos ajuda a enxergar o papel da iluminação cênica se configurando no berço do teatro ocidental, como um recurso de manipulação das imagens geradas pelo corpo em cena, por meio de um espaço arquitetural onde são distribuídos e instalados equipamentos de luz, de forma a obter angulação controlada da incidência do raio luminoso sobre o corpo humano. Este trio de fatores: espaço, fontes de luz/sombra e corpos moventes podem constituir parte dos elementos que reunidos como imagem e/ou linguagem, determinarão as bases de observação e análise crítica sobre a luz na cena. Tais elementos aparecem em quaisquer circunstâncias dos eventos cênicos e nas formas de iluminá-lo, sejam as luzes intencionalmente construídas com fins artísticos, ou distraidamente estragadas pela negligência com o tema.

Por meio desta manipulação de efeitos de luz e sombra a iluminação já era um elemento modificador do corpo, e criadora de camadas de percepção e interpretação de signos, assim como vestuários, máscaras, perucas e coturnos. Tais materialidades davam suporte para os discursos visuais da cena para criação de efeitos dramáticos e atmosféricos da cenografia da época. Em termos técnicos: espaço + luz/sombra gerada sobre o corpo + princípio ótico no equipamento (reflexão), determinavam a qualidade e a potencialidade enunciadora de significações dos efeitos de luz criados com o anaclátoras descrito por Dario Fo.

\section{Luz e sombra no espaço adensado pelo ar}

Edward Gordon Craig escreveu em detalhes um efeito de luz que ele recomendava para a cena do assassinato de Duncan, na montagem de Macbeth que Boleslavski dirigiu na Rússia em 1905:

A neblina se espalha lentamente durante a cena. Tente manter isso frio, estranho, parecendo horrível. Tente espalhar a escuridão como se fosse um véu. Então, durante o tempo em que o assassinato é cometido, [...] permita um lento, mas nítido descender da sombra, não um enfraquecimento da luz. [...]. Não fabrique 
as sombras, deixe que elas venham se vierem e puderem. Enquanto você está iluminando toda a cena. ${ }^{3}$

Craig descreve uma cenografia determinada pela atmosfera de penumbras e sombras gigantes, de forma a criar a tensão da cena lúgubre e assustadora. Sugere que uma densa neblina invada a cena muito lentamente introduzindo a quase escuridão, ao mesmo tempo, que a pouca luz existente se movimente fazendo das sombras aparições. Para tanto ele solicita um movimento sofisticado do ponto de vista operacional, "um lento, mas nítido descender da sombra, não um enfraquecimento da luz".

É interessante notar o protagonismo que a escuridão assume pela oposição ao que é fracamente iluminado, e podemos imaginar como seria necessária uma meticulosa precisão da intensidade das luzes lançadas sobre corpos e cenografia, ao mesmo tempo em que seriam envolvidos pela neblina, para instalar o predomínio do escuro na cena. Por outro lado, a pouca luz deveria ser projetada sobre cenários e corpos, para fazer com que as sombras impressas no espaço horizontal e vertical da caixa cênica italiana, pudessem configurar a atmosfera desejada da fantasmagoria que assombra o espaço do assassinato. ${ }^{4}$ Fica-nos a pergunta: onde seriam instaladas no espaço essas luzes geradoras de sombras? Pelo chão, pelas laterais da caixa cênica italiana em posições desde as coxias, pelas varandas das manobras técnicas? Não sabemos se Boleslavski realizou as sugestões do cenógrafo inglês, mas imagino que os técnicos do Teatro de Arte de Moscou estranhariam as subversões da tradição da iluminação cênica da época propostas por Craig.

O multi-artista cênico inglês também descreveu no livro Cena (Craig, 2017) outras narrativas de experimentos com pontos de luzes sobre o espaço cenográfico de seu projeto dos Screens (Craig, 2017, p. 12-14). .Realizados num protótipo em miniatura e tratados como laboratórios de simulação de efeitos e ensaios, ele experimenta procedimentos de direção da luz e ângulos de incidência sobre as superfícies das Screens.

O texto é lido no compasso em que será enunciado e, em cada deixa apontada, uma única aba ou duas de minha tela se move - ao mesmo tempo, uma das minhas lâmpadas começará a jogar sua luz com uma determinada força e de uma determinada posição e direção. (Craig, 2017, p.229)

São recorrentes nas imagens de suas gravuras e desenhos, para cenografias teatrais, as agudas aparições das sombras gigantescas geradas na horizontalidade do espaço do palco pela luz que incide sobre cenografias altas (três metros ou mais). As visualidades compostas pela luz passando por corredores construídos por telas intercaladas, ou por entre os mesmos objetos altos, também são muito comuns nos desenhos de Craig. Dessa forma, as interações da cenografia encarnada em corpos de objetos que se relacionam com a estatura humana na cena, tornam-se uma fonte de composição de imagens demarcadas pelas relações espaço, luz/sombra e pelos mo-

\footnotetext{
${ }^{3}$ The fog to sink slowly during the scene. Try to keep it cold, queer and horrible looking. Try to sink the darkness as a veil sinks. Then, during the time the murder is being done, [...] allow a slow but deliberate descending of shadow, not a lowering of light. [...]. Don't fabricate the shadows, let them come, if they will and can. While you are lighting the whole scene. Craig. The Mask, 1908. (Tradução nossa)

${ }^{4} \mathrm{~A}$ produção seria realizada no TAM - Teatro de Arte de Moscou.
} 
vimentos dos corpos bidimensionais (Screens), por onde os corpos tridimensionais de atores e atrizes se movimentariam. Para não restar dúvidas sobre a importância da consciência desta interação, Craig (2017, p. 227) afirma com pertinência absoluta:

O uso da luz para o ator só deve ser estudado pelo ator se ele observar o modo como a luz joga sua participação sutil na vida real. Se ele observar, logo perceberá que a luz cênica pode ser a melhor amiga de seu trabalho.

$\mathrm{Na}$ iluminação cênica atual existem diversos softwares de simulação de efeitos e visualização prévia das composições imagéticas que a luz concretiza ao interagir dinamicamente, e atuar com sua materialidade penetrante e silenciosa nos espaços, nas cenografias e nos corpos. Estes dispositivos são facilitadores tecnológicos com bastantes propriedades de manipulação dos efeitos de construção em 3D de arquiteturas teatrais, onde as técnicas de distribuição, angulação, intensidade, brilhos, cores podem ser testadas para estudos estéticos e poéticos dos rumos que determinarão um desenho de luz profissional e artístico. Tais tecnologias permitem ao projetista do desenho de luz, trabalhar seus efeitos em detalhadas construções, numa base experimental em seu computador pessoal em casa, onde pode se estender num tempo que não disporia dentro do teatro. Num segundo momento da execução do projeto, todo esse trabalho pode ser transferido para o painel de controle operacional na cabine do teatro, via uma interface com cabo ou wireless. A reprodutibilidade técnica no conceito de Benjamin (1993), presente na vida deste/desta profissional de forma adorável, desde que, ele/ela tenha poder aquisitivo para a compra das licenças dos referidos softwares, conforme as determinantes econômicas da vida da arte como mercadoria no regime do capitalismo tardio no qual estamos inseridos.

\section{Corpo humano como elemento visual manipulado pela luz/sombra}

Adolphe Appia enfatizava o tema de preservar a tridimensionalidade da estatura deste corpo na cena e sabe o quanto a sombra terá seu papel nesta tarefa:

\footnotetext{
Ora, a direção da luz só nos é perceptível pela sombra; é a qualidade das sombras que exprime para nós a qualidade da luz. As sombras se formam, assim, por meio da mesma luz que aquela que penetra a atmosfera. [...]. É preciso então dividir a tarefa e ter de uma parte os aparelhos encarregados de espalhar a luz, e, de outra, aqueles que pela direção precisa dos seus raios provocarão as sombras que devem nos assegurar a qualidade da iluminação. Nós chamaremos os primeiros de "luz difusa", e os segundos de "luz ativa". (Appia, 2016, p.179)
}

A presença de dois tipos luz: difusa e ativa cria o claro/escuro, configurando imagens diversas para se olhar o corpo humano e cenografia, conforme a incidência da luz numa área focal (ativa) do espaço, capaz de gerar mais sombras; ou sob a ação da luz difusa espalhada uniformemente pela cena. Das interações entre estes dois tipos de iluminação se abrem inúmeras possibilidades de criação de imagens poéticas visuais e atmosferas dramáticas, por meio dos jogos dos movimentos de luzes e sombras sobre cenários e no corpo humano que interagem com eles no espaço cênico. 
Dentre vasta literatura anglofóna sobre temas de técnica e estética em iluminação cênica, desenvolvida durante todo o século $X X$, destaco o paradigma criado pela técnica de distribuição dos equipamentos de luz pelo espaço das arquiteturas teatrais, que se iniciou com Stanley McCandless em 1932: luz de frente, contraluzes, focos e cruzados frontais posicionadas e anguladas sobre o palco e a cena a ser iluminada, desde 0 alto por meio de suportes aéreos. ${ }^{5}$

Jean Rosenthal, ex-aluna de McCandless em Yale, revolucionou a composição do desenho da luz dentro da caixa cênica italiana, ao introduzir um novo ponto de vista para a plateia, quando colocou torres laterais em pontos à esquerda e direita da caixa cênica do palco italiano. Esta nova forma de incidência de luz sobre os corpos proporcionou destaque aos movimentos dos dançarinos ao iluminar espetáculos de Martha Graham entre 1934 e 1968. Nesta nova posição as fontes de luz colocadas na mesma altura dos corpos em cena, incorporou uma nova plasticidade ao repertório de formas de iluminar a figura humana, que valoriza e amplia a lateralidade dos movimentos ágeis de bailarinos. Daí nasce toda uma estética dos corredores criando planos de profundidade pelo espaço a serem ocupados pelos corpos em movimento, disseminado de forma canônica para as estéticas de iluminação para Dança.

Aprofundando o tema da construção imagética operada pelo desenho de luz cênico, Richard Palmer (1985) apresenta um modelo importante para análise da composição, onde pensa a cena como um campo visual delimitado pelas áreas de incidência da luz, cujas angulações e direções previamente descritas, constroem junto com as superfícies de cenários, figurinos, pisos, maquiagem etc., as possibilidades infinitas de manipulação e transformação por meio de outros padrões observáveis: reflexão, absorção ou difração dos raios luminosos. Por este viés imagens, formas, cores, estampas, relações frente/fundo, e outras configurações presentes no cenário e nos corpos serão resultantes das características que regem as interações manipuladas pela iluminação cênica, que opera seu trabalho por meio dos seus atributos de direção, frequência, difusão e luminosidade, ao agir sobre os elementos que ilumina. O aprofundamento sobre estas características são objeto para outro trabalho.

$\mathrm{Na}$ atualidade pode-se perceber que a iluminação de uma cena teatral é em primeiro lugar uma impressão visual e uma construção imagética que mistura luz e sombra, cuja origem é um recurso tecnológico - fonte de luz - num espaço específico no qual uma arquitetura instaurada, busca unir palco e plateia numa conformação relacional de infinitos estímulos e informações. A iluminação se ocupa em primeiro lugar com a figura do corpo humano em cena, a presença viva e tridimensional da figura humana, sua linguagem viva e movente em busca de significar conteúdos. A fonte de luz pode ser um palito de fósforo ou o moving light de tecnologia de ponta, mas os/as criadores de luz para a cena irão sempre precisar escolher onde posicionar essa fonte de luz, em relação ao corpo da/do artista e/ou sobre o espaço cênico, determinando que ambas se movimentem no tempo certo em sintonia rítmica durante a cena, que acontece num espaço que precisa ser iluminado por fontes de luzes, que se mantenham acesas nas intensidades ideais para cada contexto da relação espaço - corpos, sejam esses últimos performers ou elementos cenográficos.

${ }^{5}$ Denominadas varas de luz no Brasil. 


\section{Referências}

APPIA, Adolphe A música e a encenação. Trad. Flávio Café. Revista do Laboratório de Dramaturgia - LADI - UnB - V. 2 e 3, Ano 1, 2016, p.158-201. Disponível em: http:// periodicos.unb.br/index.php/dramaturgias/article/view/21918/15629. Acesso em: 19 mar. 2018.

BENJAMIN, Walter A obra de arte na era de sua reprodutibilidade técnica. In: Magia e Técnica, Arte e Política. Trad. Sérgio Paulo Rouanet. São Paulo: Brasiliense, 1993.

CARDOSO, Maurício Ferreira. Geografia e espacialidade no teatro grego: as relações da luz. ABRACE 2010. Anais do VI Congresso de Pesquisa e pós graduação em artes cênicas, São Paulo.

CRAIG, Edward Gordon. Rumo a um novo teatro \& Cena. Tradução e Prefácio Luiz Fernando Ramos. São Paulo: Perspectiva, 2017.

CRAIG, Edward Gordon. The Mask. A Monthly Journal of the Art of the Theatre. Vol. 1, No. 12, February, 1908

FO, Dario. Manual Mínimo do Ator. Trad. Lucas Baldovino e Carlos David Szlak, São Paulo: Senac, 1998

FIGUEIREDO, Laura Maria de. A educação do olhar. Vídeo Aula, São Paulo, 2012. Disponível em https://www.youtube.com/watch?v=qt2JAtT3CAw . Acesso em: 19 mar. 2018.

FORJAZ, Cibele. À luz da linguagem - A iluminação cênica: de instrumento da visibilidade à "scriptura do visível" \& outras poéticas da luz. Tese de Doutorado, Escola de Comunicações e Artes, USP, São Paulo, 2013.

FORJAZ, Cibele. A linguagem da luz: A partir do conceito de Pós-Dramático desenvolvido por Hans-Thies Lehmann. In: O Pós-Dramático. Orgs: J. Guinsburg e Sílvia Fernandes. São Paulo: Perspectiva, 2013.

PALMER, Richard. The Lighting Art: The aesthetics of stage lighting design. Prentice-Hall, Inc, Englewood Cliffs, New Jersey, 1985.

SOARES, Leônidas Garcia El diálogo entre la luz y la caracterización visual: la transformación de la apariencia del intérprete en la puesta en escena occidental de 1910 a 2010. Tesis Doctorado Universidad Conplutense de Madrid, Facultad de Bellas Artes, Madrid, 2016

TUDELLA, Eduardo. Práxis Cênica como articulação de visualidade: A luz na gênese do espetáculo. Tese Doutorado, UFBA, Salvador, 2013. 
Recebido em: 21/11/2017 Aprovado em: 15/03/2018

${ }^{8}$ Fonte - http://www.sescmatogrosso.com.br/arsenal/galeria,1409,palco-giratorio-sargento-getulio-teatro-nu-ba.html 